\title{
The Impact of Public Health Expenditure on Economic Development - Evidence from Prefecture-Level Panel Data of Shandong Province
}

\author{
Lin $\mathrm{Li}^{1}$, Maoguo $\mathrm{Wu}^{1} \&$ Zhenyu $\mathrm{Wu}^{1}$ \\ ${ }^{1}$ SHU-UTS SILC Business School, Shanghai University, Shanghai, China \\ Correspondence: Maoguo Wu, SHU-UTS SILC Business School, Shanghai University, 20 Chengzhong Road, \\ Jiading District, Shanghai 201899, China.
}

Received: November 15, 2017

Accepted: November 28, 2017

Online Published: December 4, 2017

doi:10.5430/rwe.v8n2p59

URL: https://doi.org/10.5430/rwe.v8n2p59

\begin{abstract}
Public health expenditure is an indispensable part of social economy. The public has always paid close attention to public health expenditure. In order to study the quantitative relation between public health expenditure and social economic development, this paper investigates prefecture-level cities in Shandong Province, due to the unique characteristics of Shandong Province. Making theoretical and empirical contributions, this paper augments the Cobb-Douglas production function with public health expenditure and empirically analyzes economic development of prefecture- level cities in Shandong Province. A panel data set is established, followed by multivariate regression analysis. Empirical results find that public health expenditure per capita and coverage of medical insurance can significantly promote social economic development. However, the expansion and growth of the number of health institutions does not necessarily promote economic development. Instead, it may even hold back economic development by causing personnel redundancy and waste of resources. If the government transfers its investment focus from the scale and the speed of development of medical services to their fairness and efficiency, public health expenditure may vastly improve both public health and economic development.
\end{abstract}

Keywords: public health expenditure, economic development, panel data, Shandong Province

\section{Introduction}

In recent years, public health expenditure has become a topic of intense public concern. The progress made in public health development, such as the reform of the medical and health system and the improving relationship between doctors and patients in several metropolises in China, such as Beijing, Shanghai, Ningbo, and Chengdu, has improved the health of the people in those regions and has become a powerful driving force for economic development. Nowadays, Beijing, Shanghai, Ningbo, and Chengdu have become the new centers for medical resources. A new round of economic growth broke out in the areas, which are rich in medical resources, forming new economic centers. As an important factor that affects regional economic development, the study of the relationship between public health expenditure and regional economic growth also appears more and more important and quantitative research on the relationship has huge economic and social value.

Since 2007, Shandong Province's Gross Domestic Product (GDP) has been overtaken by Jiangsu province, ranking third in China. According to statistics, the total amount of public health expenditure in Shandong has always been higher than that in Jiangsu. However, because of its large population, the average public health expenditure of Shandong is much lower than that of Jiangsu. Although the Shandong provincial government pays attention to public health expenditure, there are still notable problems in actuality, and it is obvious that there are some hidden dangers in the public health system. As the research object, the characteristics of Shandong, such as its high living standards, strong economic strength, unbalanced medical resource distribution, and economic development in prefecture-level makes itself special and representative. Therefore, based on the provincial panel data of Shandong, this paper will compare and analyze the data obtained, and investigate the impact of regional public health expenditure on economic development. Based on the empirical results and the local situation, this paper provides policy implications for the local economic and public health development strategy, so as to better achieve the development goals.

The remaining part of this paper is organized as follows. Section 2 reviews related literature. Section 3 introduces the theoretical model. Section 4 is devoted to empirical analysis. Section 5 is causality analysis. Section 6 concludes the paper and proposes policy implications. 


\section{Related Literature}

Health economics is a relatively new branch of the research on economic development. A great deal of research pertains to the impact of health on economic development. Mayer et al., (2008) and Muysken (2008) argue that health has a positive effect on economic growth, where a healthy life is the prerequisite of an effective labor force, and by measuring the roles of various factors in promoting economic growth, they conclude that health factors contribute more than educational factors in improving the efficiency of workers. Based on the Granger test for panel data of 16 major Indian cities, Mohapatra and Mishra (2011) states that the growth of Gross State Domestic Product (GSDP) causes an increase in health expenditure in both the long and short run, but health expenditure only has an effect on GSDP in the long run. Balaji (2011) reaches a similar conclusion with the same methodology, specifically based on the four Southern Indian states. Whereas, based on data from different countries classified by the Human Development Index (HDI), Mohammad and Fatemeh (2015) points out that health expenditure only has a positive effect on countries with a very high HDI. Eggoh et al., (2015) confirms the conclusion by quantitative analysis of 49 African countries, stating that public health expenditure has a negative effect on economic growth of less developed African countries. By contrast, Sussex et al., (2016) points out that government and private funds for medical research and development has statistically significant positive effects on national economic development. Chen et al., (2013) investigates China's nationwide time series within a multivariate Beveridge-Nelson decomposition framework with both constant variables and cyclical variables. It argues that public health expenditure has pro-cyclical correlation with GDP growth. Meanwhile, analysis of provincial-level panel data also finds the same result, which indicates that public health expenditure can contribute to economic development. Fan (2012) and Xu (2012) conclude that health economic research in China mainly consists of three aspects: the health demand model, the efficiency and fairness problems led by health systems, and medical reform. Wang (2008), using the Arrow-Romer production function and Grossman human capital requirement model, finds that there is a positive correlation between economic growth and health expenditure in the short run, but in the long run it is suppressed because of the excessive growth of expenditure.

Research on economic growth based on the Cobb-Douglas function in China mainly focuses on labor force, education, and technology. Based on panel data of six provinces in Northern China, Zhao (2016) adopts the Cobb-Douglas production function and states that there exists a two-way causal relationship between labor force and GDP growth in four of the sample regions. Guo (2011), by extending the Cobb-Douglas function, establishes the human capital externalities model with data of material capital, human capital, and the growth level of human capital between 1984 to 2008 in Henan province, which measures their contribution rate to economic growth. Ge (2015) extends the Cobb-Douglas function by adding the dependency ratio and the weighted number of years spent in formal education. It estimates and explores the influence human capital and population bonus has on economic growth nationwide and in Shanghai between 1978 and 2012. In terms of education, a large number of papers use the Cobb-Douglas function to study the relationship between fiscal expenditure on education and economic growth. For instance, Cao (2012) finds that fiscal expenditure on the education of ethnic minorities contributes greatly to economic growth. Fu et al., (2012) uses the Denison-Madison algorithm to analyze the effects that higher education investment has on economic growth during the period between 1994 and 2008 in Liaoning Province, and found that the influence had strengthened but was still at a relatively low level in China. Gao (2013) takes GDP, capital stock, and the number of graduates in the period between 1995 and 2010 as samples, and measures the contribution to the economic growth of adult higher education and the regular higher education in Yunnan Province. It concludes that the adult higher education in Yunnan province has a low economic contribution rate, which only accounts for $40 \%$ of the ordinary higher education. In terms of science and technology, Bhorat et al., (2016) also argues that further education and training (FET), such as vocational training, other than formal tertiary degree education does not significantly contribute to economic growth in South Africa, which is similar to the findings of Gao (2013). Sun and Jiang (2014) takes the amount of activities that scientists participate in as the key explanatory factor to explore the influence of scientific personnel input on Midwest regional economic growth in China. Yang (2015) establishes an endogenous model based on the data of the period between 1999 and 2013, and conducts analysis of the interaction mechanism between technological progress, financial development, and economic growth of Sichuan and Chongqing. In the field of health economics, few theoretical studies have been conducted on this model, which is also the innovation behind this paper. Similarly, based on empirical analysis of 219 Taiwanese electronic manufacturers, Liu (2008) finds that both internal R\&D inputs and external imported technologies positively contribute to the design and sales of high-value added products in Taiwan's electronic industry from 1990 to 2003. Although there are very few theoretical studies based on this model, this paper attempts to fill in the gaps in previous research mentioned above and contributes to existing literature on health economics. 


\section{Theoretical Model}

This paper is based on Constant Elasticity of Substitution production function (CES). It only considers capital, labor, and technology in the production function, and the equation is as follows:

$$
\mathrm{Y}=\mathrm{A}\left(\delta_{1} K^{-\rho}+\delta_{2} \mathrm{~L}^{-\rho}\right)^{1 / \rho}, \mathrm{K}>0 \text { and } \mathrm{L}>0,
$$

where $\rho$ is infinitely approximating 0 , the Cobb-Douglas production function can be deduced, expression is as follows:

$$
Y_{0}=A_{0} K^{\alpha} L^{\beta} \mu,
$$

where, $Y_{0}$ is total output, $A_{0}$ is comprehensive technical level, $\mathrm{K}$ is capital input, $\mathrm{L}$ is labor input, $\alpha$ is the output elasticity of capital, $\beta$ is the output elasticity of labor, $\alpha>0, \beta>0, \mu$ is random error.

In combination with the previous literature, it can be found that the model above can be extended, not only by A, which is on behalf of the input of science and technology, which has significant economic and statistical contribution to the improvement of the social and economic output of Y. The public health input which can guarantee the high efficiency of labor in the production of social materials also has significant contribution to economic output. Thus, this paper extends the linear model. In addition to $A_{0}$, the comprehensive technical level introduces a comprehensive public health input related coefficient of $H_{0}$ (Health).

The extended function is of the following form:

$$
Y_{0}=\mathrm{A}_{0} \mathrm{H}_{0} K^{\alpha} L^{\beta} \mu,
$$

where, $Y_{0}$ is total output, A0 is comprehensive technical level,H0 is comprehensive public health input, $\mathrm{K} \alpha$ is capital input, $\beta$ is labor input, $\alpha$ is the output elasticity of capital, $\beta$ is the output elasticity of labor, $\alpha>0, \beta>0$, and $\mu$ is random error.

This paper takes the social total output "GDP" as the explained variable, and the social fixed capital as the main explanatory variables, which are represented by "Y" and "K", respectively. $A_{0}$, which indicates comprehensive technical level, is subdivided into $A_{1}$ which directly reflects the per capita input of scientific research funds, and $A_{2}$, the proportion of bachelor or higher degree holders among middle school teachers. At the same time, $\mathrm{H}$ is also subdivided into $H_{1}$, the amount of per capita medical practitioners (practicing physicians and nurses), and $H_{2}$, the average number of medical practitioners (practicing physicians and nurses) in hospitals (excluding towns and townships), and $H_{3}$, the per capita amount of hospitals (excluding towns and townships), and $H_{4}$, the percentage of people who obtain medical insurance.

After adding all variables, the model is:

$$
Y=A_{1} A_{2} H_{1} H_{2} H_{3} \mathrm{H}_{4} K^{\alpha} L^{\beta} \mu,
$$

According to the combination of $\alpha$ and $\beta$, there are three possible scenarios: (1) $\alpha+\beta>1$, it is advantageous to increase the scale of production by using existing technical level; (2) $\alpha+\beta<1$, it is not worth to expand the production scale with existing technology level; (3) $\alpha+\beta=1$, the production efficiency does increase with the existing production scale. It obtains more economic benefits only with the improvement of existing technical level.

In this paper, a regression estimation method is used to determine the contribution rate of public health input to output growth. This method assumes that the scale of compensation is constant, i.e., $\alpha+\beta=1$. Then take logarithm of both sides:

It is modified into:

$$
\ln Y=\ln A_{1}+\ln A_{2}+\ln H_{1}+\ln H_{2}+\ln H_{3}+\ln H_{4}+\alpha \ln K+\beta \ln L,
$$

$$
\ln A_{1}+\ln A_{2}+\ln H_{1}+\ln H_{2}+\ln H_{3}+\ln H_{4}+\alpha \ln K+(1-\alpha) \ln L,
$$

Manipulating equation (6) yields:

$$
\ln Y-\ln L=\ln A_{1}+\ln A_{2}+\ln H_{1}+\ln H_{2}+\ln H_{3}+\ln H_{4}+\alpha(\ln K-\ln L),
$$

Finally, the simple linear regression model can be obtained:

$$
\begin{aligned}
& \ln \frac{Y}{L}=\ln A_{1}+\ln A_{2}+\ln H_{1}+\ln H_{2}+\ln H_{3}+\ln H_{4}+\alpha \ln \frac{K}{L}, \\
& \ln y=\ln A_{1}+\ln A_{2}+\ln H_{1}+\ln H_{2}+\ln H_{3}+\ln H_{4}+\alpha \ln k,
\end{aligned}
$$

The explained variable $\mathrm{y}$ is the output value per capita (GDP per capita), and $\mathrm{k}$ is the fixed capital investment per 
capita; $\alpha$ is the coefficient of public health output per person (elasticity of capital inputs), on the basis of determination of the contribution rates of science and technology progress, labor, and capital growth inputs.

\section{Empirical Analysis}

The data for this paper is gathered from the "The Yearbook of Shandong Province", which contains relevant data of 17 prefecture-level cities in Shandong Province from the year 2000 to 2015, including data related to "GDP", "Gross Social Fixed Asset Investment", "Government R\&D Expenditure", "Total Number of High School Teachers", "The Number of Middle School Teachers with Bachelor's Degree or Above", "Medical Practitioners (chartered physicians and nurses) Number", "Number of Hospitals (not including rural clinics)", "Number of Population Covered by Medical Insurance", as well as "Total Population". The panel data set is established based on the data above.

After data cleaning and processing, GDP per capita is calculated preliminarily as the explained variable. The relevant explanatory variables include: Government R\&D Expenditure per Capita " $\mathrm{A}_{1}$ ", The Percentage of High School Teachers with Bachelor Degree or Above " $\mathrm{A}_{2}$ ", Medical Practitioners (chartered physicians and nurses) Number per Capita " $\mathrm{H}_{1}$ ", Number of Medical Practitioners (chartered physicians and nurses) per Hospital (excluding towns and townships) " $\mathrm{H}_{2}$ ", Number of Hospitals (excluding towns and townships) per Capita " $\mathrm{H}_{3}$ ", Percentage of the Population covered by Medical Insurance " $\mathrm{H}_{4}$ ", and Social Fixed Asset Investment per Capita " $\mathrm{k}$ ". According to the modified Cobb-Douglas production function, the explained variables and explanatory variables above are taken as natural logarithm, respectively.

In order to avoid the case of "spurious regression" caused by the time trend of variables, it is imperative to carry out the unit root test on the variables, to confirm the stationary variables in the panel data.

The unit root test of the panel is usually tested by the Levin-Lin-Chu unit root test (LLC) or Fisher-ADF unit root test, where the LLC properly applies to the "Same Root" situation and the Fisher-ADF is usually applied to the situation of "Different Root". In the case of no prejudgment, only if both tests reject the null hypothesis, where all panels contain the roots, can the sequence be deemed as stationary.

After an initial unit root test, it is found that the dependent variable, as well as the explanatory variables, do not contain time trends under both of the two unit root tests, which means that both variables are stationary without time trend, while the rest of the explanatory variables are stationary only in the presence of time trend; thereafter, the processing of eliminating time trends of those variables is taken, and the unit root test for the no time trend variables can then be taken. Both Levin-Lin-Chu unit root test and Fisher-ADF unit root test find that all of the time series is stationary.

For the panel data estimation methods, there are several kinds of main forms: Ordinary Least Squares (OLS), Generalized Least Squares (GLS), Pooled OLS/WLS, Fixed Effect Model, and Random Effect Model. The choice of the most suitable estimation methods requires proper parametric tests or non-parametric tests, such as Breusch-Pagan LM test for comparing OLS with random effect, Hausman test for random effect model versus fixed effect model, as well as determining whether to take GLS, pooled OLS/WLS based on the modified Wald test for group-wide heteroskedasticity, and Pesaran cross-section correlation test and Friedman cross-section correlation test etc..

Breusch-Pagan LM test for OLS versus random effect model finds that random effect model should be used in favor of OLS model. Hausman test finds that fixed effect model is more suitable than random effect model. Modified Wald test for group-wide heteroskedasticity in fixed effect model finds that there is group-wide heteroskedasticity. Pesaran test of cross-sectional independence and Friedman test of cross-sectional independence both find that there is strong presence of cross-sectional dependence in the panel.

Robustness Check is conducted to compare among results of GLS with controlled heteroskedasticity and cross-section correlation correction (GLS, Correlated), Pooled OLS within fixed effect model (SCC, FE) and fixed effect model with heteroskedasticity correction (FE, Robust). 
Robustness Check

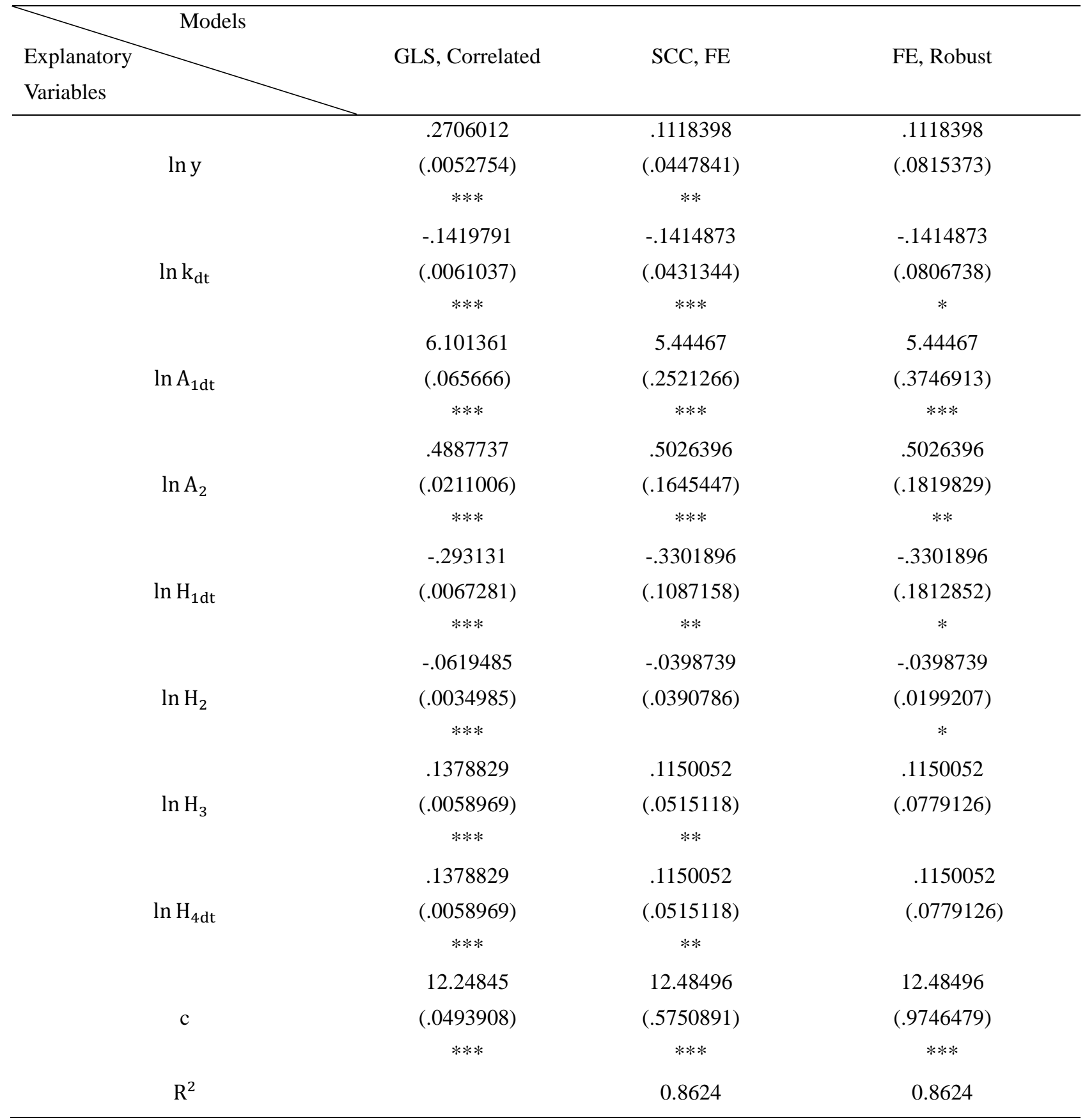

According to the statistical significance of each explanatory variable, GLS model with heteroskedasticity and cross-section correlation correction (GLS, Correlated) model should be applied for regression analysis. All the coefficients of the explanatory variables including $\alpha$ and $\mathrm{H}_{1}-\mathrm{H}_{4}$ are statistically significant at $99 \%$ confidence level, which indicates that variables have a strong explanatory effect on the dependent variable. The regression verifies that in addition to the factors Gross Social Fixed Asset Investment and Science and Technology in precedent studies, the new factor, social and public health investment introduced in this paper, also has a significant effect on social and economic development.

Among them, the coefficients of Social Fixed Asset Investment per Capita "k", The Percentage of High School Teachers with Bachelor's Degree or Above "A2", Medical Practitioners (chartered physicians and nurses) Number per Capita " $\mathrm{H}_{1}$ ", The Percentage of Population covered by Medical Insurance "H4" are positive; whereas, these 
variables have significantly positive impact on GDP per capita "Y". Among the public health expenditure variables, the Medical Practitioners (chartered physicians and nurses) Number per Capita " $\mathrm{H}_{1}$ ", The Percentage of Population covered by Medical Insurance " $\mathrm{H}_{4}$ ", have an elasticity of $48.9 \%$ and $13.8 \%$, respectively, which indicates that the abundance of medical resources per capita and the improvement of health insurance coverage can significantly promote social economic development. This result complies with the focus of "New Medicare Reform" in China.

Meanwhile, other explanatory variables, Government R\&D Expenditure per Capita " $\mathrm{A}_{1}$ ", the Number of Medical Practitioners (charted physicians and nurses) per Hospital (excluding towns and townships) " $\mathrm{H}_{2}$ ", the Number of Hospitals, (excluding towns and townships) per Capita " $\mathrm{H}_{3}$ ", have significant negative effects on GDP per capita "Y". Among which, variables related to public health; the Number of Medical Practitioners (chartered physicians and nurses) per Hospital (excluding towns and townships) " $\mathrm{H}_{2}$ ", has a negative elasticity as high as $29.3 \%$, which shows that the increasing number and scale expansion of health agencies may not be able to promote economic development. By contrast, the redundancy of personnel and resource waste may instead become an obstacle for economic development. This is also a key issue in the reform of the "supply side" on how to achieve the best match between supply and demand to solve the problems in the public health area.

\section{Causality Analysis}

Taking into account previous research and related social economics research, the causes of the negative correlation between GDP per capita and scientific research expenditure may consist of several factors. Firstly, scientific research expenditure is not entirely used on research, or on some ineffective and even invalid scientific research projects. Such expenditure may not produce material products or services to promote social economic development. Instead, it leads to "crowding out" effects and causes unreasonable resource allocation, which hinders economic development. Regarding the difficulties that the average number of hospital medical practitioners brings about in the economy, the reason may be that hospital administrative jobs are bloated, government health expenditures are greatly wasted, and funds allocated to research and development cannot always be entirely spent on that area. The reason why per capita number of hospitals has negative correlation with economic growth is that some government officers only pursue political achievements, and the expenditures are financing less relevant projects. In the long run, it will hinder economic development.

\section{Conclusion}

To achieve effective public health input, problems in the public health sector must be solved with the pursuit of efficiency and fairness in mind. The aim is to satisfy public health needs, and equally distribute limited resources.

For a long period of time, Shandong was influenced by the traditional concepts of GDP development, and some officials simply regarded solid development as GDP growth. In the field of public health, they also aimed at expanding the scale of medical services, and mistakenly regarded medical service efficiency as the speed of medical service development, development scale, the scope of services, and the quantity of service. Additionally, the unseasonable evaluation system makes officials pay attention to political performance, rather than to fairness and effectiveness. With such a short-term strategy, in the long run, even if public health investment is growing, it cannot really improve the conditions of social and public health, and may even hinder social development.

Thus, this paper argues that when government makes decisions about public health development, it should not only consider whether there are available medical resources, advanced technology, or large-scale infrastructure. There should be focus on fair, reasonable, and effective public health resource allocation, utilizing limited resources to satisfy public health needs, and trying to narrow the gap regarding public health resource allocation among cities. Although this cannot be perfectly achieved, through making laws and regulations for public health input, and improving the evaluation system, government is able to rationally allocate public health investment, and maximize its utility. As a result, residents' health levels are improved, and there is a guarantee that workers are complying on social production effectively and efficiently, continuously promoting economic development.

\section{References}

Balaji, B. (2011). Causal Nexus between Public Health Expenditure and Economic Growth in Four Southern Indian States. IUP Journal of Public Finance, 9(3), 7-22.

Bhorat, H., Cassim, A., \& Tseng, D. (2016). Higher Education, Employment and Economic Growth: Exploring the Interactions. Development Southern Africa, 33(3), 312-327. https://doi.org/10.1080/0376835X.2016.1161501

Breusch, T. S., \& Pagan, A. R. (1980). The Lagrange Multiplier Test and Its Applications to Model Specification in Econometrics. Review of Economic Studies, 47, 239-253. https://doi.org/10.2307/2297111 
Cao, F. (2012). Research on the Relation between Expenditure on Education and Economic Growth in Ethnic Autonomous Areas (in Chinese). Master Dissertation, Inner Mongolia University.

Chen, G., Inder, B., Lorgelly, P., \& Hollingsworth, B. (2013). The Cyclical Behavior of Public and Private Health Expenditure in China. Health Economics, 22(9), 1071-92. https://doi.org/10.1002/hec.2957

Dong, X. H., Wang, X., \& Li, C. (2008). Review of Research on Cobb - Douglas Production Function Theory (in Chinese). Productivity Research, 3, 148-150.

Driscoll, J. C., \& Aart, C. K. (1998). Consistent Covariance Matrix Estimation with Spatially Dependent Panel Data. Review of Economics and Statistics, 80, 549-560. https://doi.org/10.1162/003465398557825

Eggoh, J., Houenivo, H., \& Sossou, G. A. (2015). Education, Health and Economic Growth in Africa Countries. Journal of Economic Development, 40(1), 93-111.

Friedman, M. (1937). The Use of Ranks to Avoid the Assumption of Normality Implicit in the Analysis of Variance. Journal of the American Statistical Association, 675-701. https://doi.org/10.1080/01621459.1937.10503522

Fu, S. Y., Sun, S., \& Xing, H. (2012). Research on Contribution of Higher Education to Regional Economic Growth in Liaoning Province Based on Cobb-Douglas Production Function (in Chinese). Journal of Shenyang University of Technology (Social Science Edition), 5(2), 132-136.

Ge, Y. (2015). From Demographic Dividend to Human Capital Dividend (in Chinese). Master Dissertation, Shanghai Academy of Social Science.

Greene, W. (2000). Econometric Analysis. New York: Prentice-Hall.

Guo S. L. (2011). Empirical Research on Relation between Human Capital and Economic Growth in Henan Province (in Chinese). Master Dissertation, Jinan University.

Guo, Z. Y. (2015). Profit Distribution of China's Listed Manufacturing Companies Based on Cobb-Douglas Production Function (in Chinese). Master Dissertation, Harbin Institute of Technology.

Harris, R. D. F., \& Tzavalis, E. (1999). Inference for Unit Roots in Dynamic Panels Where the Time Dimension Is Fixed. Journal of Econometrics, 91, 201-226. https://doi.org/10.1016/S0304-4076(98)00076-1

Hou, Z. D. (2010). Empirical Research on the Impact of Cultural Industry Development on Economic Growth (in Chinese). Master Dissertation, Northeastern University of Finance and Economics.

Jiang, B. (2012). Empirical Research on the Demographic Dividend and Economic Growth of the Pearl River Delta Metropolitan Region in 1980 (in Chinese). Master Dissertation, South China University of Technology.

Jon, S., Yan F., Mestre-Ferrandiz, J., Pistollato, M., Hafner, M., Burridge, P., \& Grant, J. (2016). Quantifying the Economic Impact of Government and Charity Funding of Medical Research on Private Research and Development Funding in the United Kingdom. BMC Medicine, 14(2), 1-23.

Levin, A., Lin, C. F., \& Chu, C. S. J. (2002). Unit Root Tests in Panel Data: Asymptotic and Finite-Sample Properties. Journal of Econometrics, 108, 1-24. https://doi.org/10.1016/S0304-4076(01)00098-7

Liu, Y. C. (2014). Empirical Research on the Impact of Demographic Change on Economic Growth in China (in Chinese). Master Dissertation, Capital University of Economics and Business.

Pesaran, M. H. (2004). General Diagnostic Tests for Cross Section Dependence in Panels. Cambridge Working Papers in Economics, University of Cambridge.

Razmi, M. J., \& Ahmadi, F. (2015). The Effect of Health Expenditure on Economic Growth in Four Very High, High, Medium and Low Human Development Countries. Proceedings of the Multidisciplinary Academic Conference, $1-22$.

Subhalaxmi, M., \& Padmaja, M. (2011). Composition of Public Expenditure on Health and Economic Growth: A Cointegration Analysis and Causality Testing. IUP Journal of Public Finance, 9(2), 30-43.

Sun, H., \& Jiang, X. K. (2014). Research on the Impact of Scientific and Technological Talents on Regional Economic Development - Based on Comparative Analysis of East China, Central China and West China (in Chinese). Guangdong Social Sciences, 2, 15-21.

Yang, H., \& Wang, F. H. (2015). Discussion on Influence Factors of Economic Growth in Sichuan Province Based on Krongan Function (in Chinese). Times Finance, 15. 